Volume 10, No.2, March - April 2021

International Journal of Advanced Trends in Computer Science and Engineering

Available Online at http://www.warse.org/IJATCSE/static/pdf/file/ijatcse361022021.pdf

https://doi.org/10.30534/ijatcse/2021/361022021

\title{
Intuitionistic fuzzy Logic System and its Application to Global Carbon Dioxide Emissions Prediction
}

\author{
Eyoh, Imo J. ${ }^{*}{ }^{1}$, Umoeka, Ini J. ${ }^{1}$ and Udo, Edward N. ${ }^{1}$ \\ ${ }^{1}$ Department of Computer Science, University of Uyo, Uyo, Nigeria. \\ Email: *imoheyoh, iniumoeka, edwardudo@uniuyo.edu.ng
}

\begin{abstract}
In this study, a Takagi-Sugeno-Kang based intuitionistic fuzzy logic system is proposed for the prediction of global carbon dioxide emission for the first time. The intuitionistic fuzzy logic system is an integration of artificial neural network learning and intuitionistic fuzzy logic reasoning. The gradient descent back propagation is applied in the optimization of the parameters of the proposed model. The model is evaluated based on some performance metrics. Results of evaluation revealed that the intuitionistic fuzzy logic system outperforms other existing models in the literature in terms of prediction accuracy.
\end{abstract}

Key words: Carbon dioxide emissions, gradient descent backpropagation, hesitation index, intuitionistic fuzzy set.

\section{INTRODUCTION}

Climate pollution from carbon dioxide $\left(\mathrm{CO}_{2}\right)$ has been an important and challenging task globally. The forecasting of $\mathrm{CO}_{2}$ emission has attracted researches in many fields in recent times. According to [1], $\mathrm{CO}_{2}$ emission has affected countries in diverse ways including health, agriculture, economics, climate and tourism. Naturally, there should be a balance between the $\mathrm{CO}_{2}$ emitted from animals and other sources and the $\mathrm{CO}_{2}$ utilized by plants during photosynthesis, this balance has been distorted by human activities. Reference [2] pointed out that this imbalance is due to greenhouse effect (global warming, melting of polar ice sheet, rise in sea level and coastal inundation, and damage to agriculture and natural ecosystem). Many human activities have also resulted in an increasing emission of global greenhouse gas (GHG), largely by burning fossil fuels to generate electricity, heat and cool buildings, and power vehicles-as well as by clearing forests [3]. According to [3], carbon dioxide, methane, nitrous oxide, and fluorinated gases are the major greenhouse gases that people have added to the atmosphere. Appropriate methods have to be formulated in order to predict the amount of emission of these gases into the atmosphere. In this study, the prediction of $\mathrm{CO}_{2}$ emission is considered because according to
[4], $\mathrm{CO}_{2}$ constitute a significant percentage of atmospheric air pollution.

Many methods have been adopted in the literature for the prediction of $\mathrm{CO}_{2}$ emission and many have studied the relationship of $\mathrm{CO}_{2}$ with other economic indicators. For instance, [1] proposed an artificial neural network approach for the estimation of $\mathrm{CO}_{2}$ emission. The author used four input variables namely global oil, natural gas, coal and primary energy consumption to predict $\mathrm{CO}_{2}$ emission. Reference [2] adopted the autoregressive integrated moving average (ARIMA) models to forecast yearly $\mathrm{CO}_{2}$ prediction in Bangladesh. Different parametric models of ARIMA were constructed and different metrics were adopted to evaluate each ARIMA model. Reference [5] proposed a swarm intelligence methodology for the forecast of global $\mathrm{CO}_{2}$ emission. Reference [6] employed bee algorithm and artificial neural network to forecast world $\mathrm{CO}_{2}$ emission. Reference [7] presented a comparison evaluation of neural network learning algorithms for the $\mathrm{CO}_{2}$ emission prediction in Malaysia for the period 1980-2009. The comparison was made between Levenberg-Marquardt and gradient descent backpropagation algorithms for learning the parameters of neural network. Results of findings revealed that Levenberg-Marquardt algorithms showed better performance compared to gradient descent in $\mathrm{CO}_{2}$ emission prediction. Reference [8] proposed methods for forecasting $\mathrm{CO}_{2}$ emission based on machine learning methods. The authors exploited the strengths of random forest and support vector machines in their analysis. Results revealed that support vector-based method produced better forecasting results. Reference [9] predicted $\mathrm{CO}_{2}$ emission in all provinces in China using K-means cluster based logistic model. The K-means cluster analysis method was able to split the $\mathrm{CO}_{2}$ emissions into five types while the logistic model forecasted the $\mathrm{CO}_{2}$ emissions. Analysis of results revealed that the $\mathrm{CO}_{2}$ emission of China was continuously increasing. Reference [10] forecasted mediumand long-term $\mathrm{CO}_{2}$ emissions for provincial power grid using life cycle assessment and gray methods. The proposed method in [10] was found to exhibit good results in terms of prediction accuracy. Reference [11] predicted global $\mathrm{CO}_{2}$ emission using two artificial neural network models namely neural network auto-regressive with exogenous input model and the evolutionary product unit neural network model (EPUNN). The authors in [11] adopted the same input and output variables as those reported in [5]. Reference [11] concluded 
that the evolutionary approach provided more stable result in the test data than the multilayer neural network. Reference [12] forecasted $\mathrm{CO}_{2}$ emission using neural network. The authors adopted solid fuel, oil, natural gas, electricity consumption, gross domestic product and resident population obtained from the national and provincial Italian statistics as their input indicators. The authors in [12] concluded that oil and natural gas contributed immensely to $\mathrm{CO}_{2}$ emission. Reference [13] proposed a hybrid model involving fuzzy linear regression and back propagation network for global $\mathrm{CO}_{2}$ concentration prediction. The authors concluded that the forecasting accuracy of the hybrid approach was better than other models in the literature. Reference [14] applied genetic algorithm to forecast global $\mathrm{CO}_{2}$ emission. The global energy consumption dataset from 1980 to 2010 was adopted for the analysis. The authors pointed out that genetic algorithm model exhibited good performance as the predicted values were in good agreement with the observed data. Reference [15] considered two input indicators namely energy consumption and economic growth to predict $\mathrm{CO}_{2}$ emission in G20 countries using adaptive neuro fuzzy inference system (ANFIS). The authors in [15] revealed that ANFIS provided efficient $\mathrm{CO}_{2}$ emission prediction based on the two input indicators. However, ANFIS is a traditional type-1 fuzzy system and may not handle some indifference in the set definition as it is only defined by membership function with implicit assertion that non-membership function values are complementary to membership function values. This may not always be the case in real world applications. The global $\mathrm{CO}_{2}$ is highly uncertain [13] and applying type-1 fuzzy logic defined by only the membership functions may not be very suitable.

This work seeks to forecast global $\mathrm{CO}_{2}$ emission by utilizing the intuitionistic fuzzy logic system (IFLS) which incorporates separate specifications for the membership and non-membership functions and enables hesitation. According to [16], intuitionistic fuzzy set (IFS) provides an efficient means of expressing a fuzzy set where available information is insufficient to define an imprecise concept using the traditional fuzzy sets. In the same vein, [17] pointed out that using IFS provides a more natural form of decision making where more than two answers are involved compared to traditional FLS. This work adopts the same dataset as presented in [11]. The global $\mathrm{CO}_{2}$ is collected from 1980 to 2010 and includes inputs such as global oil, natural gas, coal and primary energy consumption. The contributions of this work are as follows: 1) the use of IFLS with membership and non-membership function to predict global $\mathrm{CO}_{2}$ emission for the first time. 2) The IFLS enables hesitation which is often neglected when analyzing global $\mathrm{CO}_{2}$ emission prediction. It is believed that with the independently defined membership and non-membership functions of IFS, the IFLS becomes a more powerful modelling tool compared to the traditional type-1 FLS and the prediction is more accurate and closer to human reasoning than the type-1 FLS.
To the best knowledge of the authors, this is the first work that employs IFLS for the prediction of global $\mathrm{CO}_{2}$ emission. The rest of the paper is organized as follows: In Section 2, a brief description of IFS is given. Section 3 describes the parameter update rule using gradient descent backpropagation learning algorithm. In Section 4, the evaluation of the proposed model is carried out and the conclusion is drawn in Section 5.

\section{INTUITIONISTIC FUZZY SET}

Fuzzy set, (FS), introduced by [18] is an extension of the binary set that has value 0 or 1 . In real life problems (data) where some forms of uncertainty and fuzziness are encountered, binary set may not be appropriate in such cases. The use of FS is an alternative means of addressing the problems of uncertainty in many real-world problems and can provide better solutions. For FS however, the membership function for each element has values in a closed interval $[0,1]$ and these values may not express the concept of "neither this nor that" otherwise known as neutrality or lack of knowledge. In other words, traditional FS does not incorporate hesitation degree. According to [19], the sum of membership and non-membership degree of element may be less than one, implying an extra degree of neutrality (hesitation). In such cases, the traditional FS may not suffice. Intuitionistic fuzzy set (IFS) [20] is the extended version of the traditional fuzzy set [18] and constitutes a fuzzy set with membership and non-membership functions. An interesting part about IFS is that it enables hesitation such that the addition of the membership and non-membership functions of IFS is not always complementary (an assertion implicit in traditional fuzzy set). Shown in Figure 1 is the plot of IFS. For instance, input value 4 will be $I F S_{A^{*}}(4)=[0.77,0.20]$.

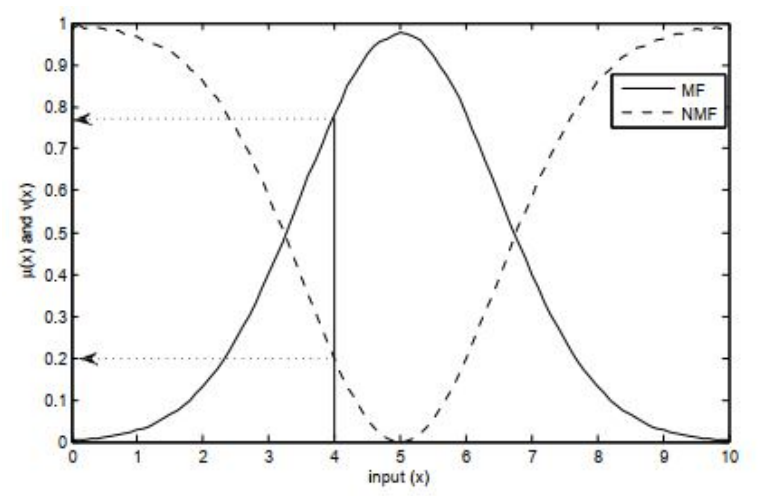

Figure 1: Intuitionistic Fuzzy Set [21]

Definition 1: Given a finite universal set, $X$, a subset $A^{\varepsilon}$ with element, $\quad x \ln A^{*}$, is specified as $A^{*}=$ $\left\{\left(x_{r} \mu_{A^{*}}(x), v_{A^{*}}(x)\right\rangle \mid x \in X\right\}$ with some hesitation index $(\pi)$ such that $\mu_{A^{*}}(x)+v_{A^{*}}(x) \leq 1$ [20].

where the function: 
$\mu_{A^{*}}: X \rightarrow[0,1]$ such that for every $x \in X$, $\mu_{A^{*}}(x) \in[0,1]$ and this represents the membership function degrees of IFS.

and the function:

$\nu_{A^{*}}: X \rightarrow[0,1]$ such that for every $x \in X$, $v_{A^{*}}(x) \in[0,1]$ and this represents the non-membership function degrees of IFS.

Obviously, for IFS, $0 \leq \mu_{A^{*}}(x)+v_{A^{*}}(x) \leq 1$. For every element, there is the $\pi$ such that $\pi_{A}(x)=1-$ $\left(\mu_{A^{*}}(x)+v_{A^{*}}(x)\right)$ which implies that 0 $\leq \pi_{A^{*}}(x) \leq 1$. This measures the degree of hesitancy of the element $x$ to the IFS $A^{*}$.

According to [20], when the membership and non-membership functions add up to 1, the traditional fuzzy set is recovered. In this case, the non-membership function is a complement to the membership function which is a special case of IFS.

i.e. for traditional FS,

$Y=\left\{\left(x, \mu_{A^{*}}(x) 1-\mu_{A^{*}}(x)\right\rangle \mid x \in X\right\}$,

then $\pi_{A^{*}}(x)=1-\left(\mu_{A^{*}}(x)+1-\mu_{A^{*}}(x)\right)$. In

essence, FS is a special case of IFS when $\pi_{A}(x)=0$.

Recently, the intuitionistic fuzzy inference has been extensively researched and applied in many problem domains such as multicriteria decision making, system identification and prediction, clustering, time series forecasting with promising results. For instance, [16] proposed an intuitionistic fuzzy inference system for predicting ozone (air pollutant) time series in Pardubice micro-region. The same authors in [22] also proposed a Takagi-Sugeno-type intuitionistic fuzzy inference system (IFIS) for regression problems. In their paper, different optimization algorithms namely gradient descent, Kaczmarz algorithm, Kalman filter and Moore-Penrose pseudo-inverse were adopted for the tuning of the model free parameters. Results reveal that Kalman filter and Moore-Penrose pseudo-inverse were more suitable for the optimization of the consequent parameters of the IFIS. Reference [23] also applied IFS with incomplete certain information on weights for multicriteria decision making. The authors pointed out that using IFS provides appropriate fuzzy decision-making procedure and satisfies a situation with incomplete certain information. Reference [24] applied IFS to model uncertainty in some regression problems. Also, [25] applied IFLS to solve a gas compression system (GCS) time series dataset with accuracy that matches that of traditional interval type-2 FLS. Reference [26] proposed an IFS for time series analysis in plant monitoring and diagnosis. Intuitionistic FS has also been applied for bankruptcy forecasting [27]. A system that adopts IFS in the rule base is known as IFLS. The IFLS consist of the intuitionistic - fuzzifier, rule base, inference engine and defuzzifier.
During training of the model, the external inputs are passed into the IFLS to obtain membership and non-membership function values of the inputs. The input-output relationships are expressed as intuitionistic fuzzy IF...THEN rules represented as:

$R_{k}:$ IF $x_{i}$ is $A_{i k}^{*}$ and $\ldots$ and $x_{n}$ is $A_{n k}^{*}$ THEN $y_{k}=$ $\sum_{i=1}^{n} w_{i k} x_{i}+b_{k}$

The generic rule can be formulated for membership and non-membership functions respectively as follows:

$R_{k}^{\mu k}:$ IF $x_{i}$ is $A_{i k g}^{* k}$ and $\ldots$ and $x_{n}$ is $A_{n k}^{* \mu}$ THEN $y_{k}=$

$\sum_{i=1}^{n} w_{i k}^{\mu k} x_{i}+b_{k}^{\mu}$

$\boldsymbol{R}_{k}^{v}:$ IF $x_{i}$ is $A_{i k}^{* v}$ and $\ldots$ and $x_{n}$ is $A_{n k}^{* \nu}$ THEN $y_{k}=$

$\sum_{i=1}^{n} w_{i k}^{v} x_{i}+b_{k}^{v}$

where $A^{* \prime}$ 's are IFS, $x$ 's are inputs, $y_{k}$ 's are outputs of each rule, $w$ is the weight and $b$ is the bias (the weight and bias are consequent parameters).

Using a $t$-norm, in this case, product $t$-norm, the inference engine combines these rules and produces a mapping from the type-1 intuitionistic fuzzy input sets to a type-1 intuitionistic fuzzy output set. For a TSK IFLS, the output of each rule is computed directly because of the functional dependencies of output variable on input variables and requires no defuzzification [22].

According to [27], the final output of a TSK-type IFLS is defined as follows:

$\mathrm{y}=(1-\beta) \sum_{k=1}^{M} f^{u} y_{k}^{\mu}+\beta \sum_{k=1}^{M} f^{V} y_{k}^{v}$

where: $f^{u}=\frac{f_{k}^{\mu^{\mu}}}{\sum_{k=1}^{M} f_{k}^{\mu^{\mu}}}$

and $f^{v}=\frac{f_{h}^{v}}{\sum_{k=1}^{M} f_{k}^{v}}$

and $\tilde{f}^{u}$ and $\tilde{f}^{v}$ are normalized firing signals for membership and non-membership functions respectively and $\beta$ is the user defined parameter that determines the magnitude of the non-membership function. It is obvious that if $\beta$ is 1 , the output is formed from only the non-membership function and if it is 0 , then only the membership function contributes to the final output.

\section{PARAMETER UPDATE RULE}

In this study, the popular gradient descent (GD) back propagation algorithm is used to tune the parameters of IFLS. The GD searches through the solution space to find a function that has the lowest possible cost. The cost function for a single output is defined as:

$$
\boldsymbol{E}=\frac{1}{2}\left(y^{\alpha}-\mathrm{y}\right)^{2}
$$


where $y^{\alpha}$ is the actual output and $\mathrm{y}$ is the model prediction. The generic parameter update rule using GD is as follows:

$$
\theta_{\mathrm{ik}}(\mathrm{t}+1)=\theta_{\mathrm{ik}}(\mathrm{t})-\gamma \frac{\delta E}{\delta \theta_{i k}}
$$

where $\gamma$ is the learning rate (step size) that must be carefully chosen to enhance stability of the learning model as a large value may lead to instability, and small values may lead to a slow learning process. The parameter $\theta$ is the generic parameter to be tuned. The learning rate and IF-indices used in this work are not adjusted. The consequent parameters include the weights $(w)$ and biases $(b)$ with the update rule:

$w_{i k}(t+1)=w_{i k}(t)-\gamma \frac{\delta E}{\delta w_{i k}}$

and $b_{k}(t+1)=b_{k}(t)-\gamma \frac{\delta E}{\delta b_{k}}$

respectively. The derivative in (7) is computed as in (9) and (10) for the weights,

$$
\begin{aligned}
& \frac{\delta E}{\delta w_{i k}}=\frac{\delta E \delta y \delta y_{k}}{\delta y \delta y_{k} \delta w_{i k}} \\
& =\sum_{k=1}^{M} \frac{\delta E}{\delta y}\left[\frac{\delta y}{y_{k}^{\mu}} \frac{y_{k}^{\mu}}{\delta w_{i k}^{p}}+\frac{\delta y}{y_{k}^{y}} \frac{y_{k}^{\mu}}{\delta w_{i k}^{y}}\right] \\
& = \\
& *\left[(1-\beta)\left(\frac{f_{k}^{\mu}}{\Sigma_{k=1}^{M} f_{k}}\right)+\beta\left(\frac{f_{k}^{v}}{\Sigma_{k=1}^{M} f_{k}}\right)\right] x_{i}
\end{aligned}
$$

while the derivative in (8) is computed as (11) and (12) respectively for the biases.

$$
\begin{aligned}
& \frac{\delta E}{\delta b_{k}}=\frac{\delta E}{\delta y} \frac{\delta y}{\delta_{\gamma_{k}}} \frac{\delta y_{k}}{\delta b_{k}} \\
& =\sum_{k=1}^{M} \frac{\delta E}{\delta y}\left[\frac{\delta y}{y_{k}^{\mu}} \frac{y_{k}^{\mu}}{\delta b_{k}^{\mu}}+\frac{\delta y}{y_{k}^{\gamma}} \frac{y_{k}^{\mu}}{\delta b_{k}^{V}}\right] \\
& \begin{array}{ll}
= & \left(y(t)-y^{a}(t)\right)
\end{array} \\
& *\left[(1-\beta)\left(\frac{f_{k}^{\mu}}{\sum_{k=1}^{M} f_{k}}\right)+\beta\left(\frac{f_{k}^{v}}{\Sigma_{k=1}^{\mu} f_{k}}\right)\right]
\end{aligned}
$$

The Gaussian function are used in the definition of the membership and non-membership functions of the IFLS. Mathematically, the Gaussian membership function is defined as follows:

$$
\mu_{i k}\left(x_{i}\right)=\exp \left(\frac{\left(x_{i}+c_{i k}\right)^{2}}{2 \sigma_{i k}^{2}}\right)
$$

which is modified as (14) and (15) to reflect membership and non-membership functions of IFS respectively.

$$
\begin{aligned}
& \mu_{i k}\left(x_{i}\right)=\exp \left(\frac{\left(x_{i}+c_{i k}\right)^{2}}{2 \sigma_{i k}^{2}}\right)\left(1-\pi_{e}\left(x_{i}\right)\right) \\
& v_{i k}\left(x_{i}\right)=\left(1-\pi_{\operatorname{var}}\left(x_{i}\right)\right)-\mu_{i k}\left(x_{i}\right)
\end{aligned}
$$

where $\pi_{e}$ and $\pi_{v a r}$ are intuitionistic fuzzy index of center and variance respectively.
The antecedent parameters are the centre $(c)$ and standard deviation $(\sigma)$ which are updated in the same manner as the weight and bias.

$$
\begin{aligned}
& c_{i k}(t+1)=c_{i k}(t)-\gamma \frac{\delta E}{\delta \varepsilon_{i k}} \\
& \text { and } \sigma_{i k}(t+1)=\sigma_{i k}(t)-\gamma \frac{\delta E}{\delta \sigma_{i k}}
\end{aligned}
$$

where the derivative $\frac{\delta E}{\delta_{\sigma_{i k}}}$ in (16) is calculated as follows:

$$
\begin{aligned}
& \frac{\delta E}{\delta \sigma_{k}}=\sum_{k} \frac{\delta E}{\delta y} \\
& *\left[\frac{\delta y}{\delta f_{k}^{\mu}} \frac{\delta f_{k}^{\mu}}{\delta \mu_{k}} \frac{\delta \mu_{i k}}{\delta v_{i k}}+\frac{\delta y}{\delta f_{k}^{v}} \frac{\delta f_{k}^{v}}{\delta v_{t k}} \frac{\delta v_{k}}{\delta c_{i k}}\right]
\end{aligned}
$$

and the derivative in (17) is computed as follows:

$\frac{\delta E}{\delta \sigma_{i k}}=\Sigma_{k} \frac{\delta E}{\delta y}\left[\frac{\delta y}{\delta f_{k}^{\mu}} \frac{\delta f_{k}^{\mu}}{\delta \mu_{k}} \frac{\delta \mu_{i k i}}{\delta \sigma_{i k}}+\frac{\delta y}{\delta f_{k}^{v}} \frac{\delta f_{k}^{v}}{\delta v_{i k}} \frac{\delta v_{\mathrm{ik}}}{\delta \sigma_{i k}}\right]$

Due to space constraint, the individual derivatives are omitted here.

\section{MODEL EVALUATION}

In order to evaluate the proposed model, three performance criteria are adopted. These include the root mean squared error (RMSE) and mean absolute error (MAE) which are defined as follows:

$$
\begin{gathered}
\mathrm{RMSE}=\sqrt{\frac{1}{N} \sum_{i=1}^{N}\left(y^{\alpha}-y\right)^{2}} \\
\mathrm{MAE}=\frac{1}{N} \sum_{i=1}^{N}\left|y^{\alpha}-y\right|
\end{gathered}
$$

where $y^{\alpha}$ is the actual measurement and $y$ is the predicted output of IFLS. The dataset for the analysis is obtained from [11] and depicted in Table 1. The data consists of oil consumption, natural gas (NG) consumption, coal consumption and primary energy (PE) consumption. The data values are normalized to lie within a small range of $[0,1]$. The data is split into training set (1980 - 2003) and testing set (2004 - 2010). 
Table 1: Actual values of global energy consumption and $\mathrm{CO}_{2}$ emission per year

\begin{tabular}{|c|c|c|c|c|c|}
\hline Year & $\begin{array}{l}\text { Oil } \\
\text { Consumption } \\
\text { (Mtoe) }\end{array}$ & $\begin{array}{l}\text { NG } \\
\text { Consumption } \\
\text { (Mtoe) }\end{array}$ & $\begin{array}{l}\text { Coal } \\
\text { Consumption } \\
\text { (Mtoe) }\end{array}$ & $\begin{array}{l}\text { PE } \\
\text { Consumption } \\
\text { (Mtoe) }\end{array}$ & $\begin{array}{l}\mathrm{CO}_{2} \\
\text { Emission } \\
(\mathrm{Mt})\end{array}$ \\
\hline 1980 & 2972.2 & 1296.9 & 1806.4 & 6624 & 19322.4 \\
\hline 1981 & 2863 & 1309.5 & 1820.6 & 6577.5 & 19073.2 \\
\hline 1982 & 2770.7 & 1312.5 & 1846.9 & 6548.4 & 18900.7 \\
\hline 1983 & 2748.3 & 1329 & 1897.7 & 6638.2 & 19072.1 \\
\hline 1984 & 2810.1 & 1440 & 1983.2 & 6960.2 & 19861 \\
\hline 1985 & 2804.7 & 1488.3 & 2056 & 7137.5 & 20246.7 \\
\hline 1986 & 2894.1 & 1503.6 & 2089.2 & 7307.5 & 20688.3 \\
\hline 1987 & 2946.8 & 1579.6 & 2169 & 7555.7 & 21344.5 \\
\hline 1988 & 3038.8 & 1654.9 & 2231.7 & 7833.5 & 22052.2 \\
\hline 1989 & 3093 & 1729.2 & 2251.2 & 8001.7 & 22470.2 \\
\hline 1990 & 3148.6 & 1769.5 & 2220.3 & 8108.7 & 22613.2 \\
\hline 1991 & 3148.2 & 1807.5 & 2196.4 & 8156 & 22606.5 \\
\hline 1992 & 3184.8 & 1817.9 & 2174.6 & 8187.6 & 22656.7 \\
\hline 1993 & 3158 & 1853.9 & 2187.6 & 8257.5 & 22710.6 \\
\hline 1994 & 3218.7 & 1865.4 & 2201.9 & 8357.6 & 22980.3 \\
\hline 1995 & 3271.3 & 1927 & 2256.2 & 8577.9 & 23501.7 \\
\hline 1996 & 3344.9 & 2020.5 & 2292.2 & 8809.5 & 24089.8 \\
\hline 1997 & 3432.2 & 2016.8 & 2301.8 & 8911.6 & 24387.1 \\
\hline 1998 & 3455.4 & 2050.3 & 2300.2 & 8986.6 & 24530.5 \\
\hline 1999 & 3526 & 2098.4 & 2316 & 9151.4 & 24922.7 \\
\hline 2000 & 3571.6 & 2176.2 & 2399.7 & 9382.4 & 25576.9 \\
\hline 2001 & 3597.2 & 2216.6 & 2412.4 & 9465.6 & 25800.8 \\
\hline 2002 & 3632.3 & 2275.6 & 2476.7 & 9651.8 & 26301.3 \\
\hline 2003 & 3707.4 & 2353.1 & 2677.3 & 9997.8 & 27508.7 \\
\hline 2004 & 3858.7 & 2431.8 & 2858.4 & 10482 & 28875.2 \\
\hline 2005 & 3908.5 & 2511.2 & 3012.9 & 10800.9 & 29826.1 \\
\hline 2006 & 3945.3 & 2565.6 & 3164.5 & 11087.8 & 30667.6 \\
\hline 2007 & 4007.3 & 2661.3 & 3305.6 & 11398.4 & 31641.2 \\
\hline 2008 & 3996.5 & 2731.4 & 3341.7 & 11535.8 & 31915.9 \\
\hline 2009 & 3908.7 & 2661.4 & 3305.6 & 11363.2 & 31338.8 \\
\hline 2010 & 4028.1 & 2858.1 & 3555.8 & 12002.4 & 33158.4 \\
\hline
\end{tabular}

Mtoe $=$ Million tonne oil equivalent

$\mathrm{Mt}=$ Million tonne 


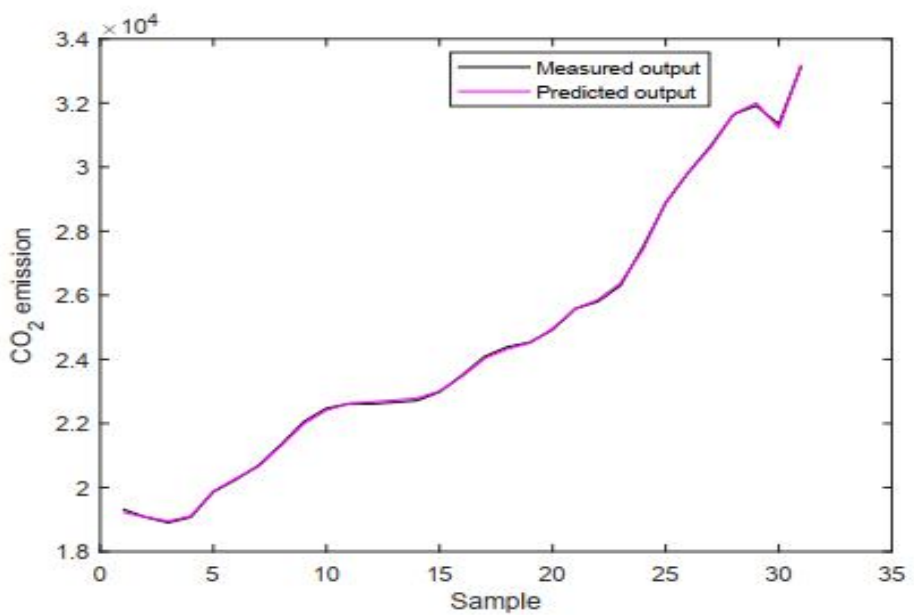

Figure 2: Actual and predicted output of global CO2 emission using IFLS

Table 2: Comparison of IFLS prediction with other models in the literature.

\begin{tabular}{|c|c|c|c|c|c|c|c|c|}
\hline $\begin{array}{l}\text { Actual } \\
\mathrm{CO}_{2} \\
\text { emissio } \\
\mathrm{n}\end{array}$ & $\begin{array}{l}\text { PSO } \\
\text { prediction } \\
{[5]}\end{array}$ & $\begin{array}{l}\text { PSO error } \\
{[5]}\end{array}$ & $\begin{array}{l}\text { MLP } \\
\text { predictio } \\
\text { n [11] }\end{array}$ & $\begin{array}{l}\text { MLP } \\
\text { error } \\
{[11]}\end{array}$ & $\begin{array}{l}\text { EPUNN } \\
\text { predictio } \\
\mathrm{n} \\
{[11]}\end{array}$ & $\begin{array}{l}\text { EPUNN } \\
\text { error } \\
{[11]}\end{array}$ & $\begin{array}{l}\text { Proposed } \\
\text { model } \\
\text { predictio } \\
\mathrm{n}\end{array}$ & $\begin{array}{l}\text { Proposed } \\
\text { model } \\
\text { error }\end{array}$ \\
\hline 19322.4 & 20953 & 1630.6 & 20940 & 1617.6 & 19324.5 & 2.1 & 19229 & 93.4 \\
\hline 19073.2 & 20084 & 1010.8 & 20031 & 957.8 & 19061.5 & 11.7 & 19075 & 1.8 \\
\hline 18900.7 & 19354 & 453.3 & 19268 & 367.3 & 18858.4 & 42.3 & 18952 & 51.3 \\
\hline 19072.1 & 19177 & 104.9 & 19083 & 10.9 & 19018.6 & 53.5 & 19106 & 33.9 \\
\hline 19861 & 19665 & 196 & 19593 & 268 & 19837.9 & 23.1 & 19880 & 19 \\
\hline 20246.7 & 19623 & 623.7 & 19548 & 698.7 & 20210.7 & 36 & 20282 & 35.3 \\
\hline 20688.3 & 20331 & 357.3 & 20290 & 398.3 & 20694.6 & 6.3 & 20657 & 31.3 \\
\hline 21344.5 & 20750 & 594.5 & 20728 & 616.5 & 21360.7 & 16.2 & 21307 & 37.5 \\
\hline 22052.2 & 21484 & 568.2 & 21498 & 554.2 & 22089.4 & 37.2 & 21988 & 64.2 \\
\hline 22470.2 & 21918 & 552.2 & 21954 & 516.2 & 22515.1 & 44.9 & 22413 & 57.2 \\
\hline 22613.2 & 22364 & 249.2 & 22422 & 191.2 & 22668.7 & 55.5 & 22619 & 5.8 \\
\hline 22606.5 & 22360 & 246.5 & 22419 & 187.5 & 22656.8 & 50.3 & 22672 & 65.5 \\
\hline 22656.7 & 22655 & 1.7 & 22728 & 71.3 & 22710.4 & 53.7 & 22723 & 66.3 \\
\hline 22710.6 & 22439 & 271.6 & 22502 & 208.6 & 22753.9 & 43.3 & 22785 & 74.4 \\
\hline 22980.3 & 22927 & 53.3 & 23016 & 35.7 & 23030.4 & 50.1 & 23005 & 24.7 \\
\hline 23501.7 & 23351 & 150.7 & 23462 & 39.7 & 23545.6 & 43.9 & 23468 & 33.7 \\
\hline 24089.8 & 23946 & 143.8 & 24090 & 0.2 & 24116.5 & 26.7 & 24031 & 58.8 \\
\hline 24387.1 & 24654 & 266.9 & 24837 & 449.9 & 24412.3 & 25.2 & 24322 & 65.1 \\
\hline 24530.5 & 24842 & 311.5 & 25037 & 506.5 & 24545.5 & 15 & 24511 & 19.5 \\
\hline 24922.7 & 25417 & 494.3 & 25644 & 721.3 & 24917.9 & 4.8 & 24954 & 31.3 \\
\hline 25576.9 & 25789 & 212.1 & 26038 & 461.1 & 25553.1 & 23.8 & 25577 & 0.1 \\
\hline 25800.8 & 25998 & 197.2 & 26260 & 459.2 & 25762 & 38.8 & 25856 & 55.2 \\
\hline 26301.3 & 26285 & 16.3 & 26564 & 262.7 & 26244.1 & 57.2 & 26378 & 76.7 \\
\hline 27508.7 & 26900 & 608.7 & 27216 & 292.7 & 27412.2 & 96.5 & 27426 & 82.7 \\
\hline
\end{tabular}


Eyoh, Imo J. et al., International Journal of Advanced Trends in Computer Science and Engineering, 10(2), March - April 2021, 710 - 718

\begin{tabular}{|l|r|r|r|r|r|r|r|r|}
28875.2 & 28145 & 730.2 & 28539 & 336.2 & 29038.9 & 163.7 & 28896 & 20.8 \\
\hline 29826.1 & 28556 & 1270.1 & 28976 & 850.1 & 29941.6 & 115.5 & 29828 & 1.9 \\
\hline 30667.6 & 28860 & 1807.6 & 29300 & 1367.6 & 30729.5 & 61.9 & 30617 & 50.6 \\
\hline 31641.2 & 29373 & 2268.2 & 29847 & 1794.2 & 31630.7 & 10.5 & 31649 & 7.8 \\
\hline 31915.9 & 29284 & 2631.9 & 29751 & 2164.9 & 31877.7 & 38.2 & 32001 & 85.1 \\
\hline 31338.8 & 28557 & 2781.8 & 28978 & 2360.8 & 31335.1 & 3.7 & 31221 & 117.8 \\
\hline 33158.4 & 29545 & 3613.4 & 30031 & 3127.4 & 32997.8 & 160.6 & 33198 & 39.6 \\
\hline $\begin{array}{l}\text { Total } \\
\text { error }\end{array}$ & & $\mathbf{2 4 4 1 9}$ & & $\mathbf{2 1 8 9 4}$ & & $\mathbf{1 4 1 2 . 2}$ & & $\mathbf{1 4 0 8 . 3}$ \\
\hline
\end{tabular}

Table 3: Comparison of IFLS prediction with Kavoosi et al. [14]

\begin{tabular}{|l|l|l|l|l|l|l|l|c|}
\hline Year & 2004 & 2005 & 2006 & 2007 & 2008 & 2009 & 2010 & Average \\
\hline Actual data & 28875. & $\begin{array}{l}29826 . \\
1\end{array}$ & $\begin{array}{l}30667 . \\
6\end{array}$ & $\begin{array}{l}31641 . \\
2\end{array}$ & $\begin{array}{l}31915 . \\
9\end{array}$ & $\begin{array}{l}31338 . \\
8\end{array}$ & $\begin{array}{l}33158 . \\
4\end{array}$ & -- \\
\hline $\begin{array}{l}\text { GA- } \\
\mathrm{CO}_{\text {2exponentia }}\end{array}$ & $\begin{array}{l}28033 . \\
1\end{array}$ & $\begin{array}{l}29481 . \\
9\end{array}$ & $\begin{array}{l}30217 . \\
8\end{array}$ & $\begin{array}{l}30859 . \\
0\end{array}$ & $\begin{array}{l}31630 . \\
7\end{array}$ & $\begin{array}{l}31728 . \\
3\end{array}$ & $\begin{array}{l}31980 . \\
5\end{array}$ & -- \\
\hline $\begin{array}{l}\text { Relative } \\
\text { error (\%) }\end{array}$ & -2.914 & -1.154 & -1.467 & -2.472 & -0.893 & 1.243 & -3.552 & $\mathbf{1 . 9 5 6}$ \\
\hline $\begin{array}{l}\text { GA- } \\
\mathrm{CO}_{2 \text { linear }}\end{array}$ & 27586. & 29624. & $\begin{array}{l}30530 . \\
8\end{array}$ & $\begin{array}{l}31324 . \\
7\end{array}$ & $\begin{array}{l}32233 . \\
9\end{array}$ & $\begin{array}{l}32171 . \\
0\end{array}$ & $\begin{array}{l}31317 . \\
7\end{array}$ & \\
\hline $\begin{array}{l}\text { Relative } \\
\text { error }(\%)\end{array}$ & -4.464 & -0.677 & -0.446 & -1.000 & 0.996 & 2.655 & -5.551 & $\mathbf{2 . 2 5 6}$ \\
\hline $\begin{array}{l}\text { Proposed } \\
\text { model }\end{array}$ & 28896 & 29828 & 30617 & 31649 & 32001 & 31221 & 33198 & \\
\hline $\begin{array}{l}\text { Relative } \\
\text { error (\%) }\end{array}$ & 0.072 & 0.006 & -0.165 & 0.025 & 0.267 & -0.376 & 0.119 & $\mathbf{0 . 1 4 7}$ \\
\hline
\end{tabular}


Figure 2 shows the actual and predicted values of global $\mathrm{CO}_{2}$ emissions using IFLS. Tables 2 and 3 show the prediction accuracy of IFLS for comparison against other models in the literature. As shown in the table 2 and Figure 2, IFLS predict $\mathrm{CO}_{2}$ emission as closely as possible to the actual values. This demonstrates an acceptable performance as depicted in the smallest absolute error. Closely following the prediction of IFLS is the EPUNN model, an evolutionary approach. Table 3 shows the comparison of IFLS prediction with the test set in [14] utilizing genetic algorithm. The relative error of IFLS is the lowest compared to the error in the linear and exponential genetic algorithm models in [14].

Table 4: Comparison of IFLs with other models in terms of Performance metrics

\begin{tabular}{|l|l|l|l|l|}
\hline Model & $\begin{array}{l}\text { Train } \\
\text { set }\end{array}$ & $\begin{array}{l}\text { Test } \\
\text { set }\end{array}$ & $\begin{array}{l}\text { Train } \\
\text { MAE }\end{array}$ & $\begin{array}{l}\text { Test } \\
\text { MAE }\end{array}$ \\
\hline $\begin{array}{l}\text { Abdelfatah } \\
\text { et al. } \text { [5] }\end{array}$ & 537.86 & 2121.4 & - & - \\
\hline $\begin{array}{l}\text { Sheta et al. } \\
\text { - MLP [11] }\end{array}$ & 33.279 & 673.97 & 33.279 & 555.33 \\
\hline $\begin{array}{l}\text { Sheta et al } \\
\text { - EPUNN } \\
{[11]}\end{array}$ & 41.52 & 100.95 & 35.75 & 79.17 \\
\hline $\begin{array}{l}\text { Proposed } \\
\text { model }\end{array}$ & 25.97 & 83.86 & 21.09 & 38.22 \\
\hline
\end{tabular}

Table 4 shows the performance of IFLS with other models in terms of RMSE and MAE metrics. As shown in the table 4, IFLS exhibits superior performance compared to other models in the literature. This is an indication that IFLS can be considered as a suitable candidate for global $\mathrm{CO}_{2}$ emission prediction.

\section{CONCLUSION}

The prediction of $\mathrm{CO}_{2}$ has been a hot topic in recent years as a result of global warming. It is therefore important to develop accurate models for predicting $\mathrm{CO}_{2}$ emission for effective management and control of air pollution. This study has presented the prediction of global $\mathrm{CO}_{2}$ emission problem using IFLS. As discussed above, IFLS is constructed using both membership and non-membership functions such that the sum of the two terms are not complementary. This allows IFLS some flexibility and the capacity to provide accurate $\mathrm{CO}_{2}$ estimate better than other models in the literature. As demonstrated through experimental analysis, the outputs of
IFLS are as close as possible to the actual global $\mathrm{CO}_{2}$ emission values.

In the future, we intend to utilize a higher order intuitionistic fuzzy logic system namely; interval type- 2 intuitionistic fuzzy logic system for the prediction of global carbon dioxide and to adapt the parameters with different learning algorithms such as particle swarm optimization, extended Kalman filter and Simulated annealing.

\section{REFERENCES}

1. A. K. Baareh. Solving the carbon dioxide emission estimation problem: An artificial neural network model, Journal of software engineering and applications, 6, pp 338-342, 2013.

2. A. Rahman and M. M. Hasan. Modeling and forecasting of carbon dioxide emissions in Bangladesh using Autoregressive Integrated Moving Average(ARIMA) models. Open Journal of Statistics, 7(4), pp 560-566, 2017.

3. United States Environmental Protection Agency (EPA) (2014). https://www.epa.gov/ghgemissions/global-greenhou se-gas-emissions-data

4. Intergovernmental Panel on Climate Change, 2014. The IPCC fifth assessment report. http://www.ipcc.ch/\#tabs-2.

5. A. Abdelfatah S. A. Mokhtar, A. Sheta, and B. Solaiman. Forecast global carbon dioxide emission using swarm intelligence. International Journal of Computer Applications, 77(12), 1, 2013.

6. M. A. Behrang, E. Assareh, M. R., Assari and A. Ghanbarzadeh. Using Bees Algorithm and Artificial Neural Network to Forecast World Carbon Dioxide Emission. Energy Sources, Part A: Recovery, Utilization, and Environmental Effects, 33(19),

2011. doi:10.1080/15567036.2010.493920.

7. H. M. Pauzi and L. Abdullah Neural network training algorithm for carbon dioxide emissions forecast: a performance comparison. In Advanced Computer and Communication Engineering Technology, Springer, Cham; 2015, pp. 717-726.

8. E. Garip and A. B. Oktay. Forecasting CO 2 Emission with Machine Learning Methods. In 2018 International Conference on Artificial Intelligence and Data Processing (IDAP), 2018, pp. 1-4. IEEE.

9. L. K. Ma, Lin, M. Guan, and M. Lin. The prediction of carbon emission in all provinces of China with the K-means cluster based Logistic model. In 2017 IEEE International Conference on Service Systems and Service Management, 2017, pp. 1-6. 
10; X. Wang, H. Qin, Y. Li, Y. Tan, and Y. Cao. A medium and long-term carbon emission forecasting method for provincial power grid. In 2014 IEEE International Conference on Power System Technology, 2014, pp. 1622-1627.

11. A. F. Sheta, N. Ghatasheh, and H. Faris. Forecasting global carbon dioxide emission using auto-regressive with exogenous input and evolutionary product unit neural network models. In 2015 6th IEEE International Conference on Information and Communication Systems (ICICS), April 2015, pp. 182-187.

12. V. Bevilacqua, F. Intini and S. Kühtz. A model of artificial neural network for the analysis of climate change. In Proceedings of the 28th International Symposium on Forecasting, 2008, pp. 22-25.

13. T. Chen and Y. C. Wang. A fuzzy-neural approach for global $\mathrm{CO2}$ concentration forecasting. Intelligent Data Analysis, 15(5), 763-777, 2011.

14. H. Kavoosi, M. H. Saidi, M. Kavoosi, and M. Bohrng. Forecast global carbon dioxide emission by use of genetic algorithm (GA). International Journal of Computer Science Issues (IJCSI), 9(5), 418, 2012.

15. A. Mardani, D. Streimikiene, Nilashi, M., D. Arias Aranda, N. Loganathan, and A. Jusoh. Energy consumption, economic growth, and $\mathrm{CO} 2$ emissions in G20 countries: application of adaptive neuro-fuzzy inference system. Energies, 11(10), 2771, 2018.

16. V. Olej, and P. Hájek. If-inference systems design for prediction of ozone time series: the case of pardubice micro-region. In International Conference on Artificial Neural Networks, 2010, pp. 1-11. Springer, Berlin, Heidelberg.

17. I. J. Eyoh, U. A. Umoh, U. G. Inyang, and J. E. Eyoh. Derivative-Based Learning of Interval Type-2 Intuitionistic Fuzzy Logic Systems for Noisy Regression Problems. International Journal of Fuzzy Systems, 1-13, 2020.

18. L. A. Zadeh. Fuzzy sets. Information and control, 8(3), 338-353, 1965.

19. P. A. Ejegwa, A. J. Akubo, and O. M. Joshua. Intuitionistic fuzzy set and its application in career determination via normalized Euclidean distance method. European Scientific Journal, 10(15), 2014.

20. K. T. Atanassov. Intuitionistic fuzzy sets. In Intuitionistic fuzzy sets, Physica, Heidelberg. 1999, pp. 1-137,

21. I. Eyoh. Interval type-2 Atanassov-intuitionistic fuzzy logic for uncertainty modelling. $\mathrm{PhD}$. dissertation, Dept. of Computer Science, University of Nottingham, 2018.
22. P. Hajek, and V. Olej. Adaptive intuitionistic fuzzy inference systems of Takagi-Sugeno type for regression problems. In IFIP International Conference on Artificial Intelligence Applications and Innovations, 2012, pp. 206-216. Springer, Berlin, Heidelberg.

23. J. Q. Wang, and H. Y. Zhang. Multicriteria decision-making approach based on Atanassov's intuitionistic fuzzy sets with incomplete certain information on weights. IEEE Transactions on Fuzzy Systems, 21(3), 510-515, 2012.

24. I. Eyoh, R. John, and G. De Maere. Interval type-2 A-intuitionistic fuzzy logic for regression problems. IEEE Transactions on Fuzzy Systems, 26(4), 2396-2408, 2017.

25. I. Eyoh, R. John, and G. De Maere. Interval type-2 intuitionistic fuzzy logic systems-a comparative evaluation. In International Conference on Information Processing and Management of Uncertainty in Knowledge-Based Systems, June 2018, pp. 687-698, Springer, Cham.

26. O. Castillo, A. Alanis, M. Garcia, and H. Arias. An intuitionistic fuzzy system for time series analysis in plant monitoring and diagnosis. Applied Soft Computing, 7(4), 1227-1233, 2007.

27. P. Hajek, and V. Olej. Defuzzification methods in intuitionistic fuzzy inference systems of Takagi-Sugeno type: The case of corporate bankruptcy prediction. In 2014 IEEE 11th International Conference on Fuzzy Systems and Knowledge Discovery (FSKD), August 2014, pp. 232-236. 